\title{
ESTUDO DA DURABILIDADE DE MISTURAS SOLO-RBI GRADE 81 COM VISTAS À APLICAÇÃO EM ESTRADAS FLORESTAIS E CAMADAS DE PAVIMENTOS CONVENCIONAIS ${ }^{1}$
}

Tiago Pinto da Trindade ${ }^{2}$, Dario Cardoso de Lima ${ }^{3}$, Carlos Cardoso Machado ${ }^{4}$, Carlos Alexandre Braz de Carvalho ${ }^{3}$, Carlos Ernesto Gonçalves Reynaud Schaefer ${ }^{5}$, Maurício Paulo Ferreira Fontes ${ }^{5}$ e Fernando Paulo Caneschi ${ }^{6}$

RESUMO - O presente artigo foi dirigido à caracterização, para fins rodoviários, do parâmetro durabilidade de três misturas solo-RBI Grade 81, a partir dos resultados dos ensaios de durabilidade por molhagem e secagem. Trabalhou-se com um solo residual maduro (solo 1) e dois solos residuais jovens ( Zona da Mata Norte de Minas Gerais, Brasil. O programa de ensaios de laboratório envolveu: (i) teor de RBI Grade 81: 6\% em relação ao peso de solo seco; (ii) energias de compactação: Proctor Normal, Intermediário e Modificado; e (iii) período de cura: 7 dias em câmara úmida. Os resultados do programa de ensaios apontaram que: (i) apenas as misturas dos solos 1 e 3 compactadas na energia do ensaio Proctor Intermediário e dos solos 2 e 3 compactadas na energia do ensaio Proctor Modificado resistiram a todos os ciclos do ensaio de durabilidade por secagem e molhagem; (ii) as misturas do solo 3 compactadas na energia do ensaio Proctor Modificado apresentaram as menores perdas de massa (inferiores a 13\%); e (iii) quanto ao aspecto durabilidade, as misturas solo-RBI Grade 81 exibem bom potencial para emprego como material de construção rodoviária.

Palavras-chave: Estabilização de solos, RBI Grade 81, estradas florestais e pavimentos convencionais e durabilidade via ensaios de secagem e molhagem.

\section{STUDY OF DURABILITY OF SOIL-RBI GRADE 81 MIXTURES FOR APPLICATION IN FOREST ROADS AND CONVENTIONAL PAVEMENT LAYERS}

\begin{abstract}
This paper addresses the characterization of three soil-RBI Grade 81 mixtures for road engineering applications using laboratory testing data from wetting and drying durability tests. One mature (soil 1) and two young (soils 2 and 3) gneiss residual soils from the Zona da Mata Norte de Minas Gerais, Brazil, were used throughout the study. The laboratory testing program comprised the following steps: (i) RBI Grade 81 content: 6\% regarding soil dry mass; (ii) compaction efforts: Standard, Intermediate and Modified Proctor; (iii) mixture specimens curing time: 7 days in acclimatized room. The testing program data supported that: (i) only tested mixtures of soils 1 and 3 compacted at the Intermediate compaction effort, and of soils 2 and 3 compacted at the Modified compaction effort endured all cycles in the durability test; (ii) mixture specimens of soil 3 compacted at the Modified Proctor compaction effort presented lower mass losses in the durability test (under 13\%); (iii) from durability testing data standpoint, soil-RBI Grade 81 mixtures are regarded as potential road engineering materials.
\end{abstract}

Keywords: Soil stabilization, RBI Grade 81, forest and conventional roads, and wetting and drying durability tests.

\footnotetext{
${ }^{1}$ Recebido em 30.03.2004 e aceito para publicação em 20.04.2005.

${ }^{2}$ Programa de Pós-Graduação em Engenharia Civil do DEC-UFV, 36570-000 Viçosa-MG, Brasil. E-mail: <tptrindade@ vicosa.ufv.br>.

${ }^{3}$ Departamento de Engenharia Civil da UFV, Viçosa-MG, Brasil. E-mail: <declima@ufv.br>.

${ }^{4}$ Departamento de Engenharia Florestal da UFV, Viçosa-MG, Brasil. E-mail: <machado@ufv.br>.

${ }^{5}$ Departamento de Solos da UFV, Viçosa-MG, Brasil.

${ }^{6}$ Graduação em Engenharia Civil, DEC-UFV, Viçosa-MG, Brasil.
} 


\section{INTRODUÇÃO}

As estradas exercem importante papel no desenvolvimento econômico e social de um país. No Brasil, o transporte rodoviário é considerado a principal via de integração do país, fundamental no escoamento da produção industrial e agrícola brasileira.

Uma informação que ilustra a importância do sistema rodoviário para a economia brasileira é que este é responsável por aproximadamente $65 \%$ do transporte de cargas e $95 \%$ do de passageiros no país, respondendo, também, pelo transporte de $70 \%$ dos produtos de consumo doméstico. (REIS, 2002).

Com relação ao setor florestal, em meados da década de 80 estimava-se a extensão da malha brasileira de rodovias em $600.000 \mathrm{~km}$ (MACHADO e MALINOVSKI, 1986), tendo esse número aumentado substancialmente com as novas ampliações das empresas florestais nas últimas duas décadas. Segundo Machado et al. (2003), os principais problemas enfrentados na construção das estradas florestais têm sido: (i) a baixa durabilidade da superfície de rolamento; e (ii) a escassez de solos locais aptos para uso como revestimento primário.

Com base nessas constatações, pode-se afirmar que são muitas as perspectivas do emprego de um agente de estabilização que possa permitir a execução do pavimento rodoviário em uma visão tradicional, bem como na forma de revestimento primário com um direcionamento maior para as vias florestais e vicinais, em geral. Assim, é de interesse realizar estudos que sejam direcionados à busca de novos materiais de construção rodoviária, em especial considerando-se a técnica de estabilização química dos solos, com a finalidade de minimizar os custos com o transporte de material de jazidas de empréstimo, bem como reduzir os impactos ambientais proporcionados pela sua exploração.

Com relação ao estabilizante que é o objeto do presente artigo, França (2003) relatou que em alguns países, como África do Sul, Israel, Itália e Portugal, o RBI Grade 81 tem sido aplicado com êxito, principalmente na construção de estradas vicinais, aumentando-se a resistência e reduzindo-se o desgaste e a formação de pó das camadas de subleito e revestimento primário. Tais aspectos são de grande interesse para o uso adequado desse estabilizante nos países tropicais, o que reforça a importância de se desenvolverem estudos de durabilidade de misturas solo-RBI Grade 81, em especial no Brasil, onde se observa uma diversidade nos processos pedogenéticos de formação de solos.

\section{MATERIAL E MÉTODOS}

\subsection{Material utilizado}

O presente trabalho foi conduzido com um solo residual jovem, pedologicamente classificado como Latossolo Vermelho-Amarelo (solo 1), e dois solos saprolíticos de gnaisse (solos 2 e 3), cujos argumentos para a sua escolha foram como se segue: (i) os solos 1 e 2 formam duas ocorrências que abrangem uma vasta área do Sudeste brasileiro; e (ii) o solo 3 é o único que se enquadra nas exigências de dosagem de misturas solo-cimento, segundo a Norma Simplificada de Dosagem da Associação Brasileira de Cimento Portland (ABCP, 1986) e a Norma de Dosagem da Associação Brasileira de Normas Técnicas (ABNT, 1992). Assim, essas misturas podem servir de referência para fins de comparação com as misturas solo-RBI Grade 81 , no que se refere ao parâmetro durabilidade. Apresenta-se, a seguir, uma descrição dos solos e locais de coleta das amostras, bem como fotografias (Figura 1) que retratam suas condições de ocorrência no campo.

- Solo 1: é um solo residual maduro, classificado pedologicamente como Latossolo Vermelho-Amarelo. Ele tem grande expressão territorial no Brasil e apresenta um horizonte B latossólico de tonalidade amarelada, estrutura granular forte e em blocos bem individualizados, aspecto bastante poroso, com textura argilo-arenosiltosa (61\% de argila, $14 \%$ de silte e $25 \%$ de areia). Trata-se de um solo classificado como A-7-5 (20), de acordo o Transportation Research Board (TRB), e LG', pela metodologia Miniatura, Compactado e Tropical (MCT). O local de coleta da amostra foi um talude de corte localizado no lado direito da rodovia que liga as cidades de Viçosa e Paula Cândido, próximo à usina de pré-misturado a frio da cidade de Viçosa;

- Solo 2: é um solo residual jovem, que se constitui no manto saprolítico, horizonte $\mathrm{C}$, resultante de um perfil de intemperismo de solos desenvolvidos do gnaisse do Pré-Cambriano, com camadas de espessuras às vezes superiores a $20 \mathrm{~m}$. Esse solo possui coloração rósea, textura areno-silto-argilosa (15\% de argila, $22 \%$ de silte e $63 \%$ de areia) e sua classificação é a que se segue: A-6 (1), de acordo com o TRB e NS', pela metodologia MCT. O local de coleta da amostra foi um talude de corte situado no lado esquerdo da rodovia que liga 
Viçosa a Paula Cândido, em frente da entrada para o bairro Romão dos Reis, na cidade de Viçosa;

- Solo 3: é, também, um solo residual jovem oriundo de um perfil de intemperismo de solos desenvolvidos do gnaisse do Pré-Cambriano. Apresenta coloração acinzentada, com granulometria areno-silto-argilosa (13\% de argila, $17 \%$ de silte e $70 \%$ de areia) e é classificado como A-2-4 (0), de acordo o TRB e NA', pela metodologia MCT. O local de coleta da amostra é um talude de corte localizado na Vila Secundino, no Campus da Universidade Federal de Viçosa (UFV), em Viçosa, MG.

Trabalhou-se com o aditivo químico denominado RBI Grade 81. Embora esse produto tenha alcançado, nos últimos anos, reconhecimento internacional como estabilizante de camadas do pavimento rodoviário, nas funções de melhoria do subleito, reforço, sub-base, base e revestimento primário, o seu uso no Brasil é, praticamente, inexistente (FRANÇA, 2003). Segundo a fabricante, o RBI Grade 81 é um produto composto por substâncias inorgânicas que agem nos solos para produzir material resistente à ação das intempéries, estáveis sob a ação de cargas e relativamente impermeáveis (ANYWAY, 2002). O produto é comercializado em sacos de $25 \mathrm{~kg}$ ou em recipientes maiores com capacidade para uma tonelada, podendo ser armazenado por até 12 meses (ANYWAY, 2002).
É um pó de cor cinza, sem odor e de característica não auto-inflamável, que apresenta pH 12,5 (na forma de pasta saturada), solubilidade em água de $0,2 / 100$ pontos e peso específico dos grãos da ordem de $2,5 \mathrm{~g} / \mathrm{cm}^{3}$.

\subsection{Preparação de amostras e programa de ensaios}

Os procedimentos empregados na preparação das misturas obedeceram às recomendações do fabricante do produto (ANIWAY, 2003) apenas adotando-se uma variação que incluiu a determinação, por meio dos resultados de ensaios de laboratório apresentados no trabalho de Trindade et al. (2005), dos tempos ótimos decorridos entre mistura e compactação dos solos considerados no presente estudo. Foram realizados ensaios de compressão nãoconfinada, com corpos-de-prova dos solos 1,2 e 3 estabilizados com $4 \%$ de RBI Grade 81, moldados nos parâmetros ótimos ( $w_{\text {ot }}$ e $\gamma_{\text {dmáx }}$ ) do ensaio de compactação Proctor Modificado, adotando-se os períodos entre mistura e compactação de $0,4,8$ e 24 horas. Os tempos ótimos decorridos entre mistura e compactação de cada um dos solos foram os que se associaram aos maiores valores de resistência à compressão não-confinada. Segundo Trindade et al. (2005), os períodos de tempo ótimos determinados em laboratório resultaram em: (i) $4 \mathrm{~h}$ para os solos 1 e 2; e (ii) compactação imediatamente após a mistura,

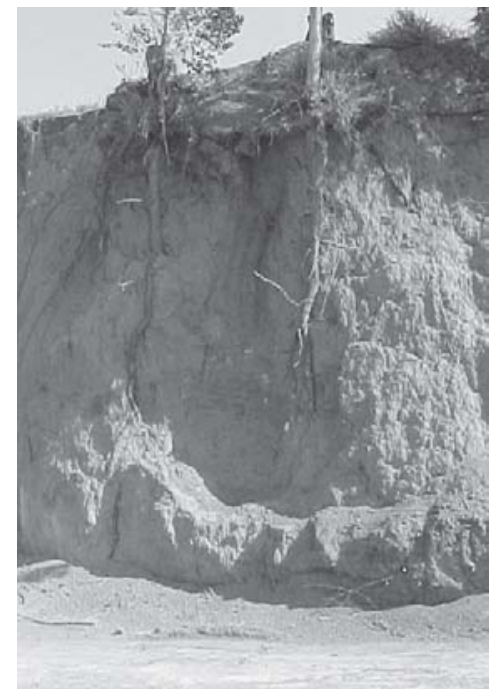

(a)

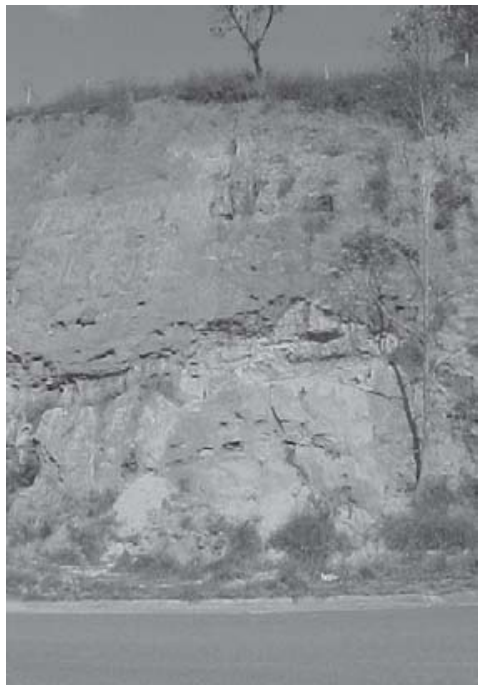

(b)

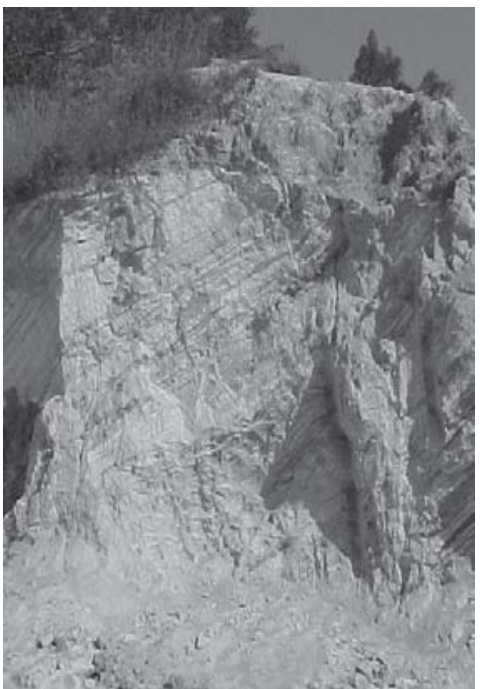

(c)

Figura 1 - Locais de coleta das amostras dos solos: (a) solo 1; (b) solo 2; e (c) solo 3. Figure 1 -Sites for soils sample collection: (a) soil 1; (b) soil 2; and (c) soil 3. 
do solo 3. Nas misturas, adicionou-se o aditivo com teor de $6 \%$ em relação ao peso de solo seco, fez-se a homogeneização da massa estabilizada e adicionouse a ela água, com posterior homogeneização, e procedeuse ao acondicionamento das amostras em sacos plásticos impermeáveis, considerando: (i) os tempos de repouso das misturas antes da compactação previamente determinados; (ii) moldagem de corpos-de-prova das misturas nos parâmetros ótimos $\left(\mathrm{w}_{\mathrm{ot}}\right.$ e $\left.\gamma_{\mathrm{dmáx}}\right)$ da energia de compactação do ensaio Proctor Modificado; e (iii) cura dos corpos-de-prova das misturas em câmara climatizada (com umidade relativa do ar superior a 95\%) por um período de sete dias. Após a cura dos corposde-prova, deu-se início aos ensaios de durabilidade por molhagem e secagem.

\subsubsection{Ensaios de compactação}

As compactações dos corpos-de-prova foram realizadas nas energias dos ensaios Proctor Normal, Intermediário e Modificado, segundo a metodologia descrita na Norma Técnica NBR 7182 (ABNT, 1986), para determinação do peso específico aparente seco máximo $\left(\gamma_{\text {dmáx }}\right)$ e da umidade ótima $\left(w_{o t}\right)$ das misturas dos solos 1,2 e 3 com $6 \%$ de RBI Grade 81 .

\subsubsection{Moldagem dos corpos-de-prova}

Os corpos-de-prova foram moldados nas energias anteriormente citadas para a realização dos ensaios de durabilidade por molhagem e secagem. Os corposde-prova foram compactados por processo dinâmico, utilizando-se o molde do ensaio de compactação Proctor, ou seja, um molde cilíndrico de $10 \mathrm{~cm}$ de diâmetro e $12,73 \mathrm{~cm}$ de altura (aproximadamente, $1.000 \mathrm{~cm}^{3}$ de volume), obedecendo-se às especificações apresentadas no Quadro 1.

Para aceitação dos corpos-de-prova foram fixados os seguintes limites em sua preparação (DNER, 1994a): peso específico aparente seco máximo $\pm 0,30 \mathrm{kN} / \mathrm{m}^{3}$; e umidade ótima $\pm 0,5 \%$.

\subsubsection{Ensaios de durabilidade por molhagem e secagem}

Os ensaios de durabilidade através da perda de massa por molhagem e secagem foram executados segundo a metodologia proposta pelo Departamento Nacional de Estradas de Rodagem e descrita no Método de Ensaio DNER-ME 203 (DNER, 1994b). Originalmente, o ensaio foi desenvolvido para se avaliar a durabilidade, através da perda de massa, de corpos-de-prova de misturas solo-cimento compactados na energia do ensaio Proctor Normal e submetidos a um período de cura de sete dias em câmara úmida, antes de serem submetidos a 12 ciclos consecutivos de molhagem, secagem e escovação com escova de fios de aço achatados (ABCP, 1986). No entanto, no presente trabalho, tendo em vista a recomendação do fabricante de que as misturas soloRBI Grade 81 devem ser compactadas na energia do ensaio Proctor Modificado (ANYWAY, 2003), trabalhouse, também, com as energias de compactação dos ensaios Proctor Intermediário e Modificado.

\section{RESULTADOS E DISCUSSÃO}

Nos Quadros 2 a 4, encontram-se os parâmetros ótimos de compactação determinados para as misturas dos solos 1, 2 e 3, compactados nas energias dos ensaios Proctor Normal, Intermediário e Modificado.

Os resultados apresentados nos Quadros 2 a 4 mostram que o aumento da energia de compactação foi responsável por incrementos nos valores de peso específico aparente seco máximo e reduções nos valores de umidade ótima das misturas. Observou-se, também, que os maiores valores de peso específico aparente seco máximo relacionam-se ao solo 3 , de características granulares ( $70 \%$ de areia). Em contrapartida, o solo 1 , que possui $61 \%$ de argila, apresentou os maiores valores de umidade ótima. No que diz respeito aos parâmetros ótimos de compactação, os materiais estudados neste trabalho apresentaram comportamento comumente relatado em trabalhos clássicos da Mecânica dos Solos (VARGAS, 1977; SOUSA, 1980; PINTO, 2000).

Quadro 1 - Parâmetros e equipamentos utilizados nos ensaios de compactação Table 1 - Compaction tests parameters and equipments

\begin{tabular}{|c|c|c|c|}
\hline \multirow{2}{*}{$\begin{array}{l}\text { Características Inerentes a cada } \\
\text { Energia de Compactação }\end{array}$} & \multicolumn{3}{|c|}{ Energia de Compactação Empregada } \\
\hline & Normal & Intermediária & Modificada \\
\hline Soquete & Pequeno & Grande & Grande \\
\hline Número de camadas & 3 & 3 & 5 \\
\hline Número de golpes por camada & 26 & 21 & 27 \\
\hline Energia (MN.m/m³) & 0,59 & 1,29 & 2,69 \\
\hline
\end{tabular}

R. Árvore, Viçosa-MG, v.29, n.4, p.591-600, 2005 
Quadro 2 - Resultados dos ensaios de compactação: solo 1 com 6\% de RBI Grade 81 Table 2 - Compaction tests data: soil 1 with 6\% of RBI Grade 81

\begin{tabular}{lcc}
\hline Energia de Compactação & $\gamma_{\text {dmáx }}\left(\mathrm{kN} / \mathrm{m}^{3}\right)$ & $\mathrm{w}_{\text {ot }}(\%)$ \\
\hline Energia Normal & 13,85 & 30,78 \\
Energia Intermediária & 14,68 & 28,19 \\
Energia Modificada & 15,17 & 27,32 \\
\hline
\end{tabular}

Quadro 3 - Resultados dos ensaios de compactação: solo 2 com 6\% de RBI Grade 81 Table 3 - Compaction tests data: Soil 2 with $6 \%$ of RBI Grade 81

\begin{tabular}{lcc}
\hline Energia de Compactação & $\gamma_{\text {dmáx }}\left(\mathrm{kN} / \mathrm{m}^{3}\right)$ & $\mathrm{w}_{\text {ot }}(\%)$ \\
\hline Energia Normal & 14,81 & 20,35 \\
Energia Intermediária & 16,23 & 18,13 \\
Energia Modificada & 16,92 & 16,11 \\
\hline
\end{tabular}

Quadro 4 - Resultados dos ensaios de compactação: solo 3 com 6\% de RBI Grade 81 Table 4 -Compaction tests data: soil 3 with $6 \%$ of RBI Grade 81

\begin{tabular}{lcc}
\hline Energia de Compactação & $\gamma_{\text {dmáx }}\left(\mathrm{kN} / \mathrm{m}^{3}\right)$ & $\mathrm{w}_{\mathrm{ot}}(\%)$ \\
\hline Energia Normal & 16,08 & 14,08 \\
Energia Intermediária & 17,02 & 12,74 \\
Energia Modificada & 18,12 & 12,10 \\
\hline
\end{tabular}

De posse dos parâmetros ótimos de compactação de cada uma das misturas, partiu-se, então, para a moldagem dos corpos-de-prova para a realização dos ensaios de durabilidade por molhagem e secagem.

Os resultados ilustrados nos Quadros 5, 6 e 7 revelam que as únicas misturas que resistiram aos 12 ciclos do ensaio de durabilidade foram as que se seguem: solo 1 , com $6 \%$ de RBI Grade 81 compactado na energia Intermediária (perda de massa acumulada na ordem de $16 \%$ ); solo 2 com $6 \%$ de RBI Grade 81 compactado na energia Modificada (perda de massa acumulada da ordem de 22\%); e solo 3, com 6\% de RBI Grade 81 compactado nas energias Intermediária e Modificada (perdas de massa acumuladas da ordem de 20 e 13\%, respectivamente).

Observou-se também que, com o aumento da energia de compactação, ocorreram reduções na perda de massa das misturas, exceto nas misturas do solo 1 com o aditivo químico, em que houve inversão de resultados entre as energias do ensaio Proctor Intermediário e Modificado. A maior durabilidade associada a uma menor energia de compactação observada no solo 1 pode ser explicada por meio do modelo de representação da estrutura de solos argilosos compactados, proposto por Lambe (1958). Esse autor afirmou que, a partir de determinado nível de energia de compactação aplicada ao corpo-de-prova, há tendência de suas partículas se orientarem de forma paralela, com diminuição das distâncias entre elas, resultando num material mais denso. No entanto, como afirmou Melo (1985), à medida que as partículas tendem a se orientar de forma paralela, pode ocorrer formação de lamelas que podem levar a um descolamento precoce de camadas do corpo-de-prova, reduzindo, assim, a sua resistência ao desgaste, o que pode ter ocorrido no presente caso. Esse fenômeno é comum em solos lateríticos argilosos, podendo-se citar como exemplo um estudo conduzido com um Latossolo Roxo desenvolvido sobre o basalto na bacia do Paraná, onde Carvalho et al. (1981) constataram, por meio da observação de amostras em microscópico eletrônico, utilizando-se a técnica de Microscopia eletrônica de Varredura (MEV), que, após uma compactação empregando a energia do ensaio Proctor Normal, o solo apresentou fraturas segundo as superfícies de menor resistência, e os vazios intersticiais foram substituídos por vazios fissurais orientados perpendicularmente ao eixo da compactação.

R. Árvore, Viçosa-MG, v.29, n.4, p.591-600, 2005 
Quadro 5 - Resultados dos ensaios de durabilidade por secagem e molhagem: solo 1 com 6\% de RBI Grade 81 Table 5 - Data from wetting and drying durability tests: soil 1 with $6 \%$ of RBI Grade 81

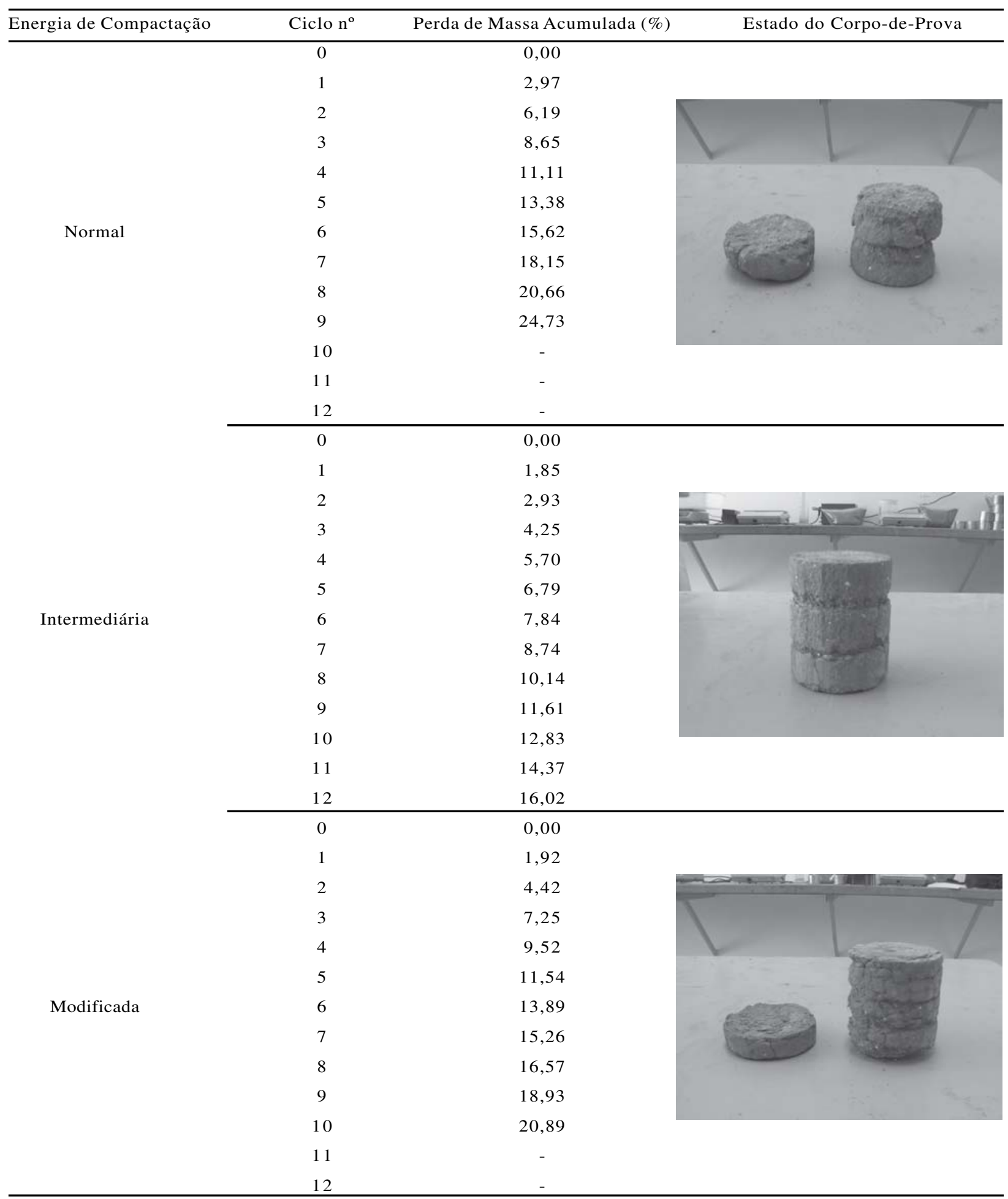

R. Árvore, Viçosa-MG, v.29, n.4, p.591-600, 2005 
Quadro 6 - Resultados dos ensaios de durabilidade por secagem e molhagem: solo 2 com 6\% de RBI Grade 81 Table 6 - Data from wetting and drying durability tests: soil 2 with $6 \%$ of RBI Grade 81

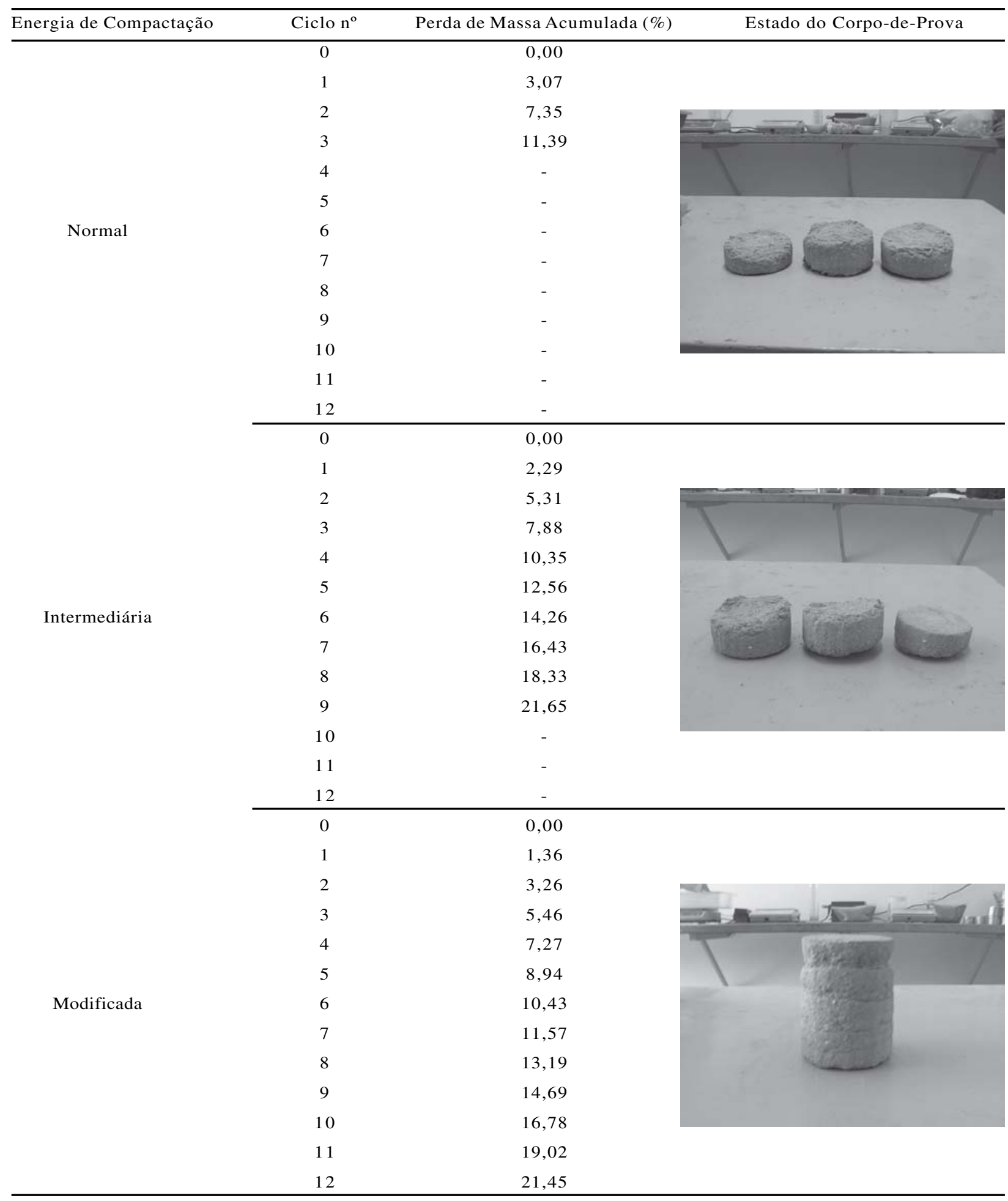

R. Árvore, Viçosa-MG, v.29, n.4, p.591-600, 2005 
Quadro 7 - Resultados dos ensaios de durabilidade por secagem e molhagem: solo 1 com 6\% de RBI Grade 81 Table 7 - Data from wetting and drying durability tests: soil 1 with $6 \%$ of RBI Grade 81

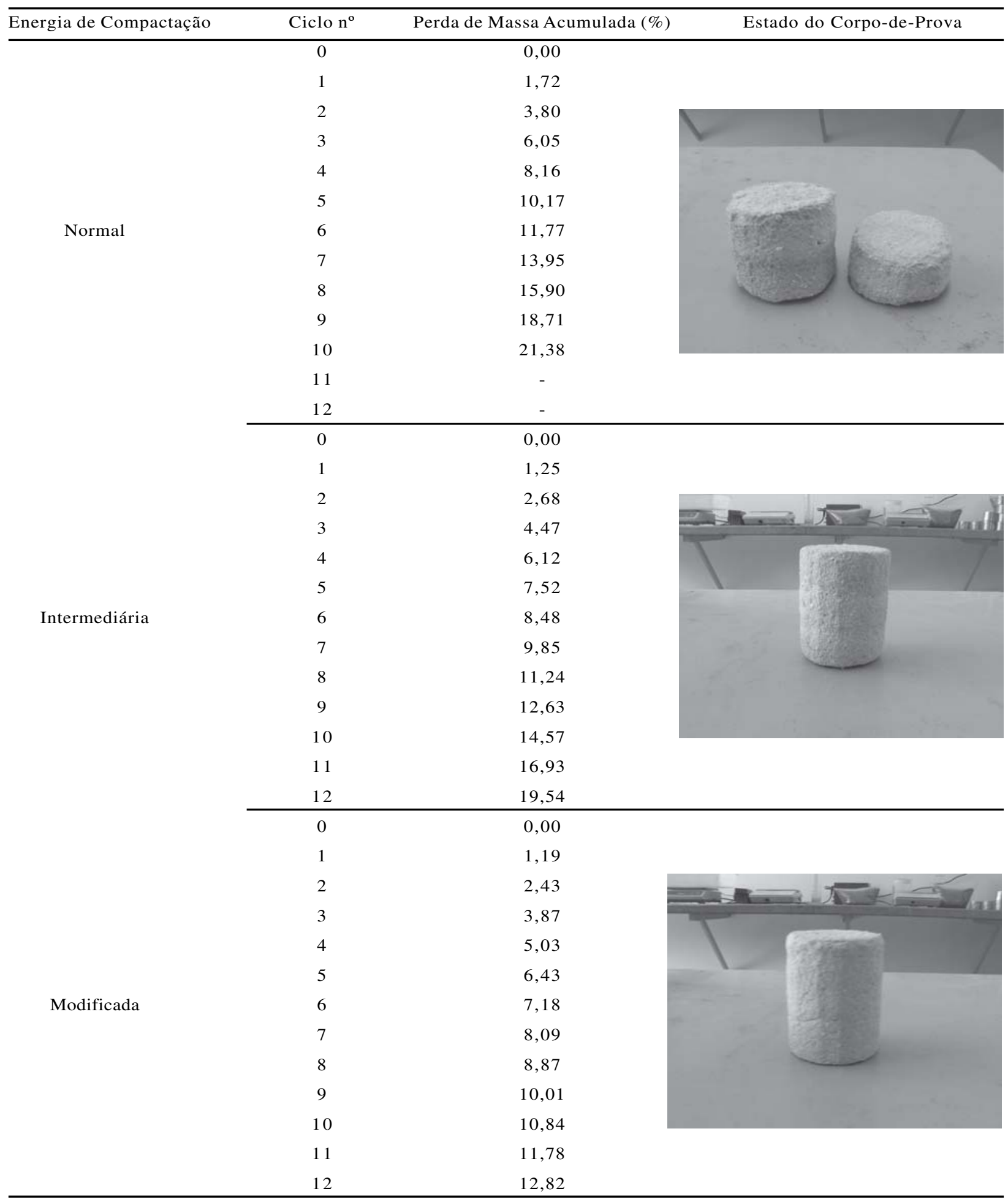

R. Árvore, Viçosa-MG, v.29, n.4, p.591-600, 2005 


\section{CONCLUSÕES}

Apenas os corpos-de-prova obtidos das combinações dos solos 1, 2 e 3 estabilizados com $6 \%$ de aditivo e compactados nas energias dos ensaios Proctor Intermediário (solos 1 e 3) e Proctor Modificado (solos 2 e 3 ) resistiram a todos os ciclos dos ensaios de durabilidade por molhagem e secagem.

Verificou-se, também, que o solo 3 estabilizado com $6 \%$ de RBI Grade 81 e compactado na energia do Proctor Modificado apresentou a maior durabilidade por molhagem e secagem, dentre as misturas aqui analisadas, com uma perda de massa acumulada da ordem de $13 \%$.

A análise dos resultados dos ensaios de durabilidade realizados indica que a estabilização de solos com RBI Grade 81 pode ser uma técnica de interesse para fins rodoviários. No entanto, o emprego desse produto, em especial considerando-se os solos finos, requer estudos prévios de dosagem em laboratório para cada tipo de solo considerado.

\section{AGRADECIMENTOS}

À Coordenadoria de Aperfeiçoamento de Pessoal de Nível Superior (CAPES), pela concessão da bolsa de estudo ao primeiro autor; à SIF, pelo apoio financeiro; à empresa TECFLORA S.A., pelo fornecimento de amostras de RBI Grade 81 utilizadas no presente trabalho; e à Universidade Federal de Viçosa, através do Departamento de Engenharia Civil, por ter possibilitado a execução do presente trabalho.

\section{REFERÊNCIAS BIBLIOGRÁFICAS}

\section{ASSOCIAÇÃO BRASILEIRA DE CIMENTO} PORTLAND. Estudo Técnico 35: Dosagem das misturas de solo-cimento: Normas de dosagem. 3. ed. São Paulo: [s.n.], 1986. 51 p.

\section{ASSOCIAÇÃO BRASILEIRA DE NORMAS} TÉCNICAS -ABNT. NBR 7182: Solo: ensaio de compactação: Procedimento. Rio de Janeiro: 1986. $10 \mathrm{p}$.

\section{ASSOCIAÇÃO BRASILEIRA DE NORMAS} TÉCNICAS -ABNT. NBR 12253: Solo-cimento: dosagem para emprego como camada de pavimento: Procedimento. Rio de Janeiro: 1992. 4 p.
ANYWAY SOLID ENVIRONMENTAL SOLUTIONS LTD. KEREM MAHARAL. Frequently asked questions. Israeli Office, 50 Bezalel Street, Ramat-Gan, 52521 Israel, 2002. 2 p.

ANYWAY SOLID ENVIRONMENTAL SOLUTIONS LTD. KEREM MAHARAL. Guide to the construction of pavement layers and stabilized materials using RBI Grade 81 natural soil stabilizer. Israeli Office, 50 Bezalel Street, Ramat-Gan, 52521 Israel, 2003. 8 p. Disponível em http://www.anywaysolutions.com/. Acesso em: 22 mar. 2005.

CARVALHO, A. et al. Caracterização mineralógica, morfológica e geotécnica de alguns solos lateríticos desenvolvidos sobre basaltos na Bacia do Paraná. In: SIMPÓSIO BRASILEIRO DE SOLOS TROPICAIS EM ENGENHARIA, 1981, Rio de Janeiro. Anais..., Rio de Janeiro: [s.n.], 1981. p. 340-381.

DEPARTAMENTO NACIONAL DE ESTRADAS DE RODAGEM - DNER. DNER-ME 202: Solocimento: moldagem e cura de corpos-de-prova cilíndricos: Método de ensaio. Rio de Janeiro: 1994a. 7 p.

\section{DEPARTAMENTO NACIONAL DE ESTRADAS} DE RODAGEM- DNER. DNER-ME 203: Solocimento: determinação da durabilidade através da perda de massa por molhagem e secagem: Método de ensaio. Rio de Janeiro: 1994b. 4 p.

FRANÇA, F. C. Estabilização química de solos para fins rodoviários: estudo de caso com o produto "RBI Grade 81". 2003. 104 f. Dissertação (Mestrado em Engenharia Civil), Universidade Federal de Viçosa, Viçosa, 2003.

LAMBE, T. W. The structured of compacted clays. Journal of Soil Mechanics and Foundation Division, ASCE, v. 84, n. SM2, p. $1654-1$ to $1654-34,1958$.

MACHADO, C. C.; MALINOVSKI, J. R. Rede viária florestal. Curitiba: FUPEF, 1986. 157 p.

MACHADO, C. C.; SANT'ANNA, G. L.; PEREIRA, R. S. Pavimentação de estradas florestais: emprego do alcatrão de madeira de eucalipto. Revista da Madeira, n. 73, p. 56-62, 2003.

R. Árvore, Viçosa-MG, v.29, n.4, p.591-600, 2005 
MELO, F. G. Compactação de aterros de barragens de terra. Lisboa: Laboratório Nacional de Engenharia Civil (LNEC), 1985. $106 \mathrm{p}$.

PINTO, C. S. Curso básico de mecânica dos solos. São Paulo: Oficina de Textos, 2000. $247 \mathrm{p}$.

REIS, R. M. M. Misturas asfálticas tipo SMA para pavimentos de alto desempenho submetidos a tráfego pesado. 2002. 111 f. Dissertação (Mestrado em Engenharia Civil), Universidade de São Paulo, São Paulo, 2002.
SOUSA, M. L. Pavimentação rodoviária. 2 . ed. Rio de Janeiro: Instituto de Pesquisas Rodoviárias, 1980. 361 p. 1 v.

TRINDADE, T. P. et al. Estabilização química do subleito de estradas: influência do tempo decorrido entre a mistura e a compactação na resistência mecânica de misturas solo-RBI Grade 81. Revista Árvore, v. 29, n. 3, p. 413-418, 2005.

VARGAS, M. Introdução à mecânica dos solos. São Paulo: MCgraw-Hill do Brasil, 1977. 509 p. 